\title{
Erythropoietin-producing Lung Cancer
}

\author{
Isao Miyoshi ${ }^{1}$, Yoshiki Uemura ${ }^{2}$, Tokiko Nakai ${ }^{2}$, Masanori Daibata ${ }^{3}$, \\ Madani Ly ${ }^{4}$ and Pierre Saintigny ${ }^{5}$
}

Key words: lung cancer, erythropoietin, erythrocytosis

(Inter Med 48: 389-390, 2009)

(DOI: 10.2169/internalmedicine.48.1681)

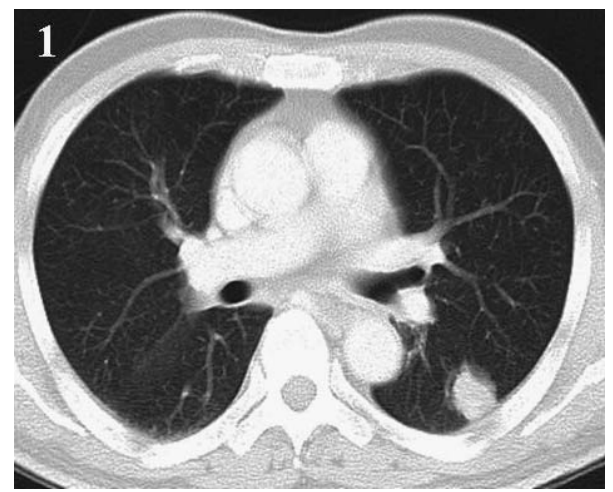

Picture 1. Chest CT scan showing a nodular lesion in the left lower lung.

A 68-year-old Japanese man (never smoker) underwent total gastrectomy for stomach cancer in November 1998. In March 2005, he was treated for macrocytic anemia by injections of vitamin $B_{12}$. In August 2006, he was found to have chronic myelomonocytic leukemia associated with iron deficiency anemia. Blood examination showed a red cell count $5.05 \times 10^{12} / \mathrm{L}$, hemoglobin $11.4 \mathrm{~g} / \mathrm{dL}$, hematocrit $38.5 \%$, white cell count $17 \times 10^{9} / \mathrm{L}$ with $34 \%$ monocytes, and platelet count $80 \times 10^{9} / \mathrm{L}$. Abdominal computed tomography revealed moderate splenomegaly. The anemia was normalized with oral iron tablets, while the leukemia remained non-progressive without chemotherapy. Then, curiously enough, the blood examination started to show erythrocytosis. In November 2007 , the red cell count was $7.28 \times 10^{12} / \mathrm{L}$, the hemoglobin was $17.2 \mathrm{~g} / \mathrm{dL}$, and hematocrit was $56.1 \%$. The bone marrow was hyperplastic with $36.2 \%$ erythroblasts and $33 \%$ monocytes. In the same month, chest radiography and computed tomography incidentally disclosed a nodular lesion, about $2 \mathrm{~cm}$ in diameter, in the left lower lung (Picture 1). The lesion was diagnosed as lung cancer by transbronchial lung biopsy. Review of a previous chest radiograph taken in
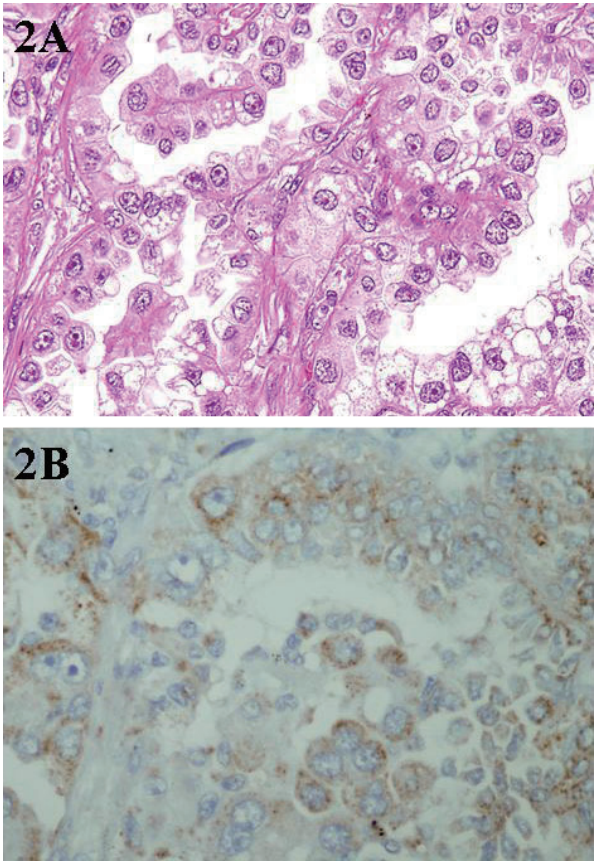

Picture 2. Section from the lung tumor showing (A) papillary adenocarcinoma (Hematoxylin and Eosin staining) and (B) erythropoietin-positive carcinoma cells (anti-erythropoietin antibody).

January 2006 suggested the presence of a barely visible opacity in the same location. Left lower lobectomy was performed and pathological examination confirmed that the tumor was an adenocarcinoma with mixed papillary and bronchioloalveolar subtypes (Picture 2A), with no nodal or metastatic involvement (stage 1A). After removal of the tumor, erythrocytosis subsided. When reacted with antibodies against erythropoietin and erythropoietin receptor by immunohistochemistry, many of the carcinoma cells were positive for the expression of erythropoietin (Picture 2B) but the expression of erythropoietin receptor appeared negative. Thus,

${ }^{1}$ Tosa Tamura Hospital, Kochi, ${ }^{2}$ Kochi Medical Center, Kochi, ${ }^{3}$ Department of Medicine, Kochi University School of Medicine, Nangoku, ${ }^{4}$ Hospital Tenon, Paris, France and ${ }^{5}$ Hospital Avicenne, Bobigny, France

Received for publication September 9, 2008; Accepted for publication November 7, 2008

Correspondence to Dr. Masanori Daibata, daibatam@kochi-u.ac.jp 
the patient's erythrocytosis was found to be secondary to the secretion of erythropoietin from the lung cancer. Unfortunately, the serum erythropoietin level had not been measured. Erythropoietin is a key factor promoting tumor angio- genesis and it may have enhanced the tumor growth in our patient. Bronchogenic carcinoma manifesting paraneoplastic erythrocytosis is very rare.

\section{(C) 2009 The Japanese Society of Internal Medicine http://www.naika.or.jp/imindex.html}

